\title{
Rules of engagement: developing the online tutor
}

\author{
Aileen McGuigan* and Lucy Golden
}

School of Education, Social Work and Community Education, University of Dundee, Dundee, UK

(Received 20 February 2012; final version received 17 June 2012)

This paper considers professional development in a context that is familiar and problematic to teaching teams in tertiary education everywhere, that of delivering online programmes with an ever-decreasing complement of staff. The Teaching Qualification Further Education (TQFE) teaching team at University of Dundee confronted the reality of reduced staff numbers by centralising tutoring and support for programme participants. The new system involves standardising tutoring as far as possible through generic email, blog and microblog accounts, all badged "TQFE-Tutor" and staffed on a roster basis. Once the new "rules of engagement" via TQFE-Tutor were in place, it became clear that in addition to benefits in terms of student support, there were other unintended positive consequences: opportunities for informal professional development for staff and the promotion of effective team working. The experience of collective tutoring has facilitated collaboration on a range of innovations within online learning. This paper describes the evolution of the TQFE-Tutor innovation and reports upon a small scale study which was carried out to gather the views of the tutor team working with TQFE-Tutor. The authors conclude that the centralisation of communication and tutoring on the TQFE programme has been highly beneficial in terms of professional development for the team.

Keywords: confronting reality; sustainable models; online tutoring; sharing knowledge; CPD

\section{Introduction}

The Teaching Qualification Further Education (TQFE) is a professional teaching qualification programme for in-service lecturers in the tertiary education sector and has been delivered online at University of Dundee since 2006, to about 200 participants per annum. TQFE-Tutor incorporates a University email account (Office 365), a purpose-built blog (Wordpress) and a microblog (Twitter). It unites the nine members of the programme team, now working "as one" via these media tools on a roster basis. It is intended to enhance the learning of programme participants, supplementing and intensifying the programme's teaching and learning materials and contributing towards the three core elements of an educational experience: the social, cognitive and teaching presences, as explored by Garrison and colleagues (Garrison and Anderson 2003; Garrison, Anderson, and Archer 1999; Garrison and Cleveland-Innes 2005). Staff on the TQFE programme almost exclusively conduct their work online and it is the authors' view that this is therefore the ideal location for their own professional development, a view shared with

*Corresponding author. Email: a.mcguigan@dundee.ac.uk 
Boud (1999) and various later commentators, such as Cornelius and Macdonald (2008).

\section{Background}

The familiar UK tertiary education landscape of cutbacks, smaller staff teams and restructured administrative support was the backdrop for the creation of a different kind of communication and tutoring system at University of Dundee. The prevalent belief (Fidishun n.d.; Richardson, Long, and Woodley 2003; Yorke 2004; Zembylas 2008) suggested that online learners essentially require a personal tutor to overcome feelings of isolation and uncertainty caused by distance and lack of peers physically learning alongside them; prior to the advent of TQFE-Tutor, the TQFE teaching team belonged to the same school of thought. The concept of the collective TQFETutor as a sustainable model emerged in response to the shrinking academic team, halving from eight full-time equivalent staff to just four in a period of five years (nine tutors are currently employed on the programme, with varying portions of time allocated, from a half day per week up to full-time).

A pilot study conducted within the programme in 2009/2010 suggested that a blog might usefully be employed for the teaching team to manage some sustainable communication with the cohort collectively and following upon the success of that trial, in 2010/2011 the TQFE-Tutor blog/email/microblog system was launched, applying to each the collective principles which had proved useful on the pilot blog. Since then, all tutoring on the programme has been conducted via TQFE-Tutor. Programme participants are very positive about the support they receive from TQFETutor and appreciate the speedy turnaround times afforded by the system. The team is able to guarantee a response to any enquiry - to the generic email or blog - within two working days (see Figure 1 for the logo by which all TQFE-Tutor utilities are badged).

\section{The many roles of the online tutor}

The authors recognise the fundamental role of online programme communications in the support of learners, especially in the context of distance learning. TQFE-Tutor allows for a seamless approach as far as the programme participants are concerned all their enquiries and submissions being dealt with in a timely and consistent way, while the tutor team maintains an overall awareness of the learner experience, through the shared utilities. The system facilitates the various roles the online tutor has to undertake, as described by Markel (1999 in McLoughlin and Lee 2010):

[the] major role of the teacher is arguably to facilitate this dynamic learning process, assisting learners in drawing their own links between their learning and the 'real world'; other roles may be that of 'consultant', 'guide' and 'resource provider'.

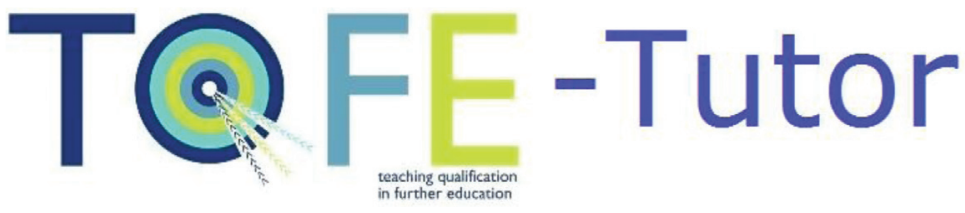

Figure 1. TQFE-Tutor logo. 


\section{A. McGuigan and L. Golden}

Much has been written about the changing role and relationships between online tutors and learners. Discussing the role of the online lecturer, Rice (2011, elaborating on earlier work by Collison et al. 2000) argues:

Rather than the Sage on the Stage or Guide on the Side, you're going to see a growing embrace of the Sage on the Side model. The need for an instructor with high-quality, in-depth domain knowledge (The Sage) will never go away.

It is clear that when it comes to e-learning, another raft of skills is required of the subject experts, those necessary for successful teaching and communicating in the online environment (Morrison 2012).

In an environment where email is very much the norm, a further onerous role, that of personal correspondent, frequently falls to the personal tutor. In the context of the TQFE programme pre-innovation, there were more than 40 co-correspondents (participants) in each personal tutor's group, necessitating the fielding of huge numbers of emails daily. Programme participants were not inclined to seek their own answers to questions when they could bat the relevant question - in an email - to a tutor who would feel obliged to respond. In some cases participants appeared to develop an unhealthy dependency on the individual personal tutor rather than becoming independent learners, emailing long messages several times a day. In addition, participant feedback suggested that not all participants received the support they felt they needed.

A major advantage of having a teaching team comprised of a large number of academics is the wide and diverse range of knowledge, experience and skills such a team collectively holds. However, a team profile of staff with different time commitments on a programme can also be a weakness, particularly in the online context. For instance, email may not be dealt with in a timely way when the tutor has other commitments. This could also be stressful for the personal tutor, accruing an increasing stream of emails requiring attention. Because TQFE-Tutor is staffed on a roster basis, long waits for learners are eradicated and there is an equitable sharing of the full tutoring role, including all correspondence.

\section{Putting the team at the centre of their own professional development}

The "rules of engagement" for academics on TQFE-Tutor roster duties are underpinned by a series of Frequently Asked Questions (FAQs) which have been collectively drawn up by the team and are updated as necessary, following on from discussion at periodic team meetings. The involvement of the teaching team in all aspects of the development has promoted "ownership" of the TQFE-Tutor utilities and for positive team values to emerge and develop. All team members are encouraged to contribute to the continuing development of the utilities; all have remarked upon professional development gains from the system.

In addition to collective "ownership" of TQFE-Tutor by the team, there is professional development in the more dynamic and on-going sense for all of the team to keep moving with the different sectors and student groups that they (and/or the TQFE participants, who are also lecturers) have, to avoid what Julia Fotheringham referred to as "the danger of educational inertia" (in a presentation on e-pedagogy at University of Dundee, 2012). Many university staff may have been teaching and assessing in a fairly similar way for many years while around them the cultural, political, social, technological world is constantly developing and evolving. Enthusiastic 
"early adopters" of technological innovation, like the TQFE programme team at University of Dundee, concur with Staker's (2011) view that:

online learning has the potential to be a disruptive force that will transform the ... structure that has dominated ... into a new model that is student-centric, highly personalized for each learner, and more productive. (Staker 2011)

TQFE-Tutor enables the teaching team to keep abreast of online learning developments. It opens opportunities for continuous professional development (CPD) through peer work using such tools as JING, Adobe connect, Fireworks, blogs and so on, not removed from the context of teaching and promoting learning but ensconced within it. Through various strands of the TQFE-Tutor system team members are able to review each other's work and find better ways to foster and encourage learning online and at a distance.

\section{A typical shift on TQFE-Tutor}

While at certain times of the academic year such as close to assessment deadlines several staff are needed simultaneously to deal with a high volume of enquiries to TQFE-Tutor, an average three hour shift may include answering 10-12 emails, responding to two or three blog postings and monitoring the arrival of assessments within the Virtual Learning Environments (VLEs) submission system (SafeAssign). The emails and/or blog postings may include confirmation of assessment submission and require a simple reply with the relevant marker copied in. There may be queries about submissions, teaching observation arrangements or how to access something such as recordings of online tutorials. Other messages may report a broken hyperlink in the online learning materials or include a request for an extension due to sensitive family issues. A programme participant may be confused by or disagree with assessment feedback or may want to know more about a theory they do not understand. In all these cases, while copying in others as appropriate, the duty tutor works out, implements and communicates the solution, switching between the roles of facilitator of the learning process, supporter and resource provider (Markel 1999, in McLoughlin and Lee 2010). In this way a "needy" participant benefits from collective support and the workload is shared evenly.

\section{Evaluating the TQFE-Tutor system}

In academic session 2011/2012, when the new TQFE-Tutor system was launched on the TQFE programme, it won University of Dundee's Honorary Graduates' Award for Innovative Teaching. The usual end of module questionnaires were used to evaluate the TQFE-Tutor system and it was clear that it had been a success as far as the programme participants were concerned. Anecdotal evidence also began to emerge, recognising the value of the system as a sustainable model and about its efficacy in delivering informal professional development to its academic team. With the support of funding from JISC's Assessment and Feedback programme, a project ran throughout the academic session 2011/2012 - Evaluating feedback for e-learning: centralised tutors, or EFFECT - with the objective of robustly evaluating the system, to probe deeper into the informal preliminary findings, potentially enabling further streamlining and providing lessons which may be useful for others involved in online 


\section{A. McGuigan and L. Golden}

programme development and delivery. The study below grew out of the EFFECT project and considers the potential of the TQFE-Tutor model for professional development use.

\section{Method}

Data were collected from two different sources: (1) a focus group discussion with three members of the programme team (S1, S2 and S3), facilitated by one of the current authors (F) and (2) an interview with a new member of the team (S4), also conducted by author F. Both events were recorded and the recordings transcribed. Drawing on Ritchie and Spencer's (1994) framework analysis and the work of Srivastava and Thomson (2009), the two recordings were reviewed several times for the authors to familiarise themselves with the content and to draw up a thematic framework.

For the focus group, the following questions/prompts were used:

(1) What development opportunities does the TQFE-Tutor offer and do you personally consider them to be beneficial?

(2) How do the benefits of TQFE-Tutor measure up against any informal staff development available on other programmes you teach on, in the college sector or here in the University?

(3) Could TQFE-Tutor provide further opportunities for the team? Either other things we could be doing on the blog, or the email system that could improve our staff development?

(4) What can be done to future proof the system against institutional and other external changes?

In the case of the interview, the interviewee (S4) was encouraged to talk about the effect of TQFE-Tutor upon her experience as a new tutor on the programme.

\section{Reliability issues}

The facilitator of the focus group and the interview (i.e. the sources of both data sets discussed below) is the Programme Director of the TQFE programme, so could be regarded as predisposed to find favourable evidence about TQFE-Tutor. Similarly, bias was possible on the part of the team members who took part in the study; they may not have felt able to express negative opinions in the presence of the Programme Director. However, everyone who took part in the study - facilitator and participants alike - was aware of the potential precariousness of their positions as "insiders", i.e. those with specialist knowledge of the research topic. In the view of the authors, this insider knowledge does not invalidate the research. This is a small study evaluating the TQFE-Tutor system: at this stage in its evolution, only team members have sufficient knowledge about it to proffer useful opinions on the topic.

\section{Discussion}

Grouped under "strengths" and "weaknesses", seven different subthemes emerged from the data; see Figure 2. Each of the subthemes is discussed below. 


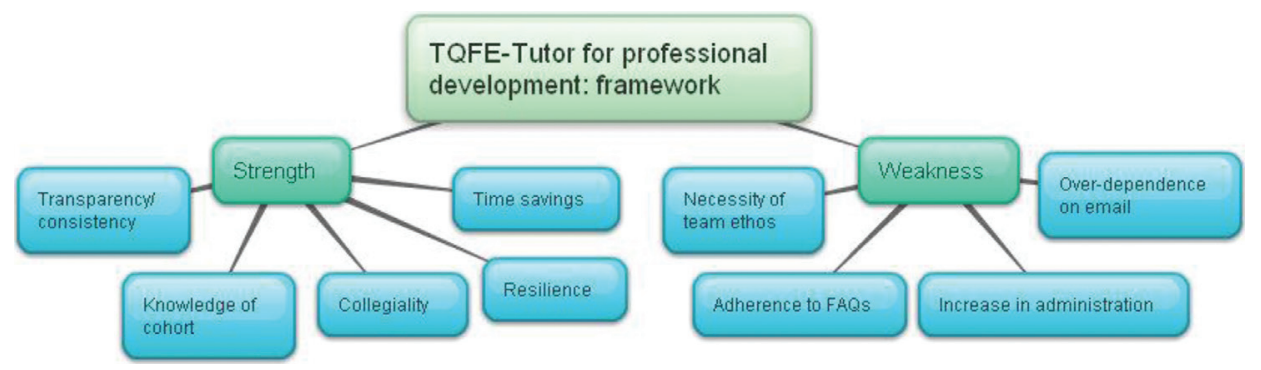

Figure 2. TQFE-Tutor for professional development: framework.

\section{Transparency and consistency}

It was recognised that as well as benefits to the learners (alluded to above), the transparency and consistency TQFE-Tutor engenders is advantageous to the tutor team and a major strength of the system. "It's not the secret garden syndrome" S1 remarked; "there's a transparency to what we're doing". S3 concurred:

... on another distance learning programme I work on, very part-time and there it's very much that each member of staff has their module and their marking ... people want to feel they're not exposed in any way, but there's no real benefit in learning from that.

It is a common characteristic of online programmes for there to be a good deal of private email correspondence between tutor and learner. Where pastoral guidance is concerned it is understandable for this correspondence to be conducted privately (in the occasional instances where this is necessary one-to-one support is available via the TQFE-Tutor system too), but it is less easy to see any reason for privacy in matters relating to the content of the programme of study. In fact in the authors' opinion, it is often the case that this kind of discussion could be much to the benefit of many within the cohort if it was conducted openly. There is of course a strong case for protecting learners, who may not want to expose a perceived weakness to the cohort and of course these matters should be dealt with sensitively. However, as the focus group discussion strongly indicated, it was very useful to have the opportunity to see all the queries and each other's responses to the same. The collective TQFE-Tutor system impels the sharing of good practice - the focus group recognised that this led to a valuable consistency of approach across the team - vital to the success of an online programme.

As a relatively new university lecturer $\mathrm{S} 4$ was clear that she was able to gain a good understanding of marking practices from interaction with, and observation of, tutors who had been teaching in HE for longer, including being able to "borrow useful phrases" especially ideas on how to phrase critical feedback while keeping a participant feeling motivated and encouraged. She spoke positively about the benefits for her of working alongside more experienced colleagues who had the overview and knowledge about the academic cycle of the programme. Even more important to her was the opportunity provided by TQFE-Tutor to read several of the team members' marking and feedback on the same module, when she came to marking her own assignments. While a mentor-tutor is in place for new lecturers, providing the "clinical supervision" recognised as useful for new online tutors (Bennett and Marsh 2002), the wider perspective gained by such an open and transparent approach was very helpful in opening up a range of feedback and feed-forward and avoiding any particular preoccupations which the individual mentor may have. 


\section{A. McGuigan and L. Golden}

Such benefits singled out for comment by $\mathrm{S} 4$ are not limited to new members of staff, as is clear from the focus group with the more established staff members: S3 remarked, "I looked at one [email] and thought, "that's a difficult one to answer" ... it had all kinds of things brought up in it and I thought how can you begin to unravel all that and I looked a couple of hours later and you'd replied to it'. The facilitator commented, "We know what the rules are, but sometimes it's difficult to construct a diplomatic and brief email"; the idea of compiling a bank of email responses surfaced during the focus group discussion too and is one that the team plans to develop further.

\section{Collegiality}

The focus group explored the idea of some of their own social needs being met by TQFE-Tutor, the system providing a sense of belongingness that was not previously present. "You do feel in touch. Although I'm not up [in Dundee] much, I do still feel in touch with the rest of the team and there is contact" (S1); "it does keep you ... part of that bigger picture" (S3). It is widely recognised that a lot of staff development happens informally - so-called "water cooler" conversations - and these opportunities are frequently lost in the context of online programme delivery. As Cornelius and MacDonald (2008) discuss in the context of the Open University, opportunities for such serendipitous staff discussion must happen online in an online programme and this is what TQFE-Tutor offers.

When posting on the TQFE-Tutor blog, S4 felt that her response was in line with the team response, made "in the spirit of a group of people"; she described a "... feeling of unity", identifying with TQFE-Tutor as an entity unifying the various programme tutors.

\section{Knowledge of cohort}

Compared with the old personal tutor system, where a staff member's knowledge of the cohort was limited to their own allocation of tutees, TQFE-Tutor enables a much broader understanding of the whole year group. S2 commented, "You see more of issues from other perspectives ... it's like we're all appreciating what each other are dealing with". This of course chimes with idea of collegiality (discussed above), but is also about gaining useful insights into the student body. S3 went on to remark:

... rather than focusing on your own marking group or your own participants ... you see more of issues from other perspectives ... I think that for me has been really beneficial. To make me; well, we're all responsible for the full cohort and their problems or issues, their successes.

Speaking about the TQFE-Tutor blog, S4 explained that the collective TQFE-Tutor approach affords a full view of the cohort:

... rather than just my own marking group who may not be those who are the very capable ones, happy to ask questions and communicate online. It is an advantage for all staff to see learners engaging and responding online and helps to motivate tutors as well as benefiting those participants who want the answers but are less confident about asking online-as in any group. 
Widening this out into the full team, with the "bigger picture" afforded by TQFETutor, all members have opportunities to spot trends and/or common misunderstandings and adapt materials appropriately, offering learners dynamic support.

\section{Time saving}

The many time saving benefits of TQFE-Tutor were returned to time and again in the focus group discussion and in the interview. Various members remarked on the repetitions that are avoided by the use of TQFE-Tutor. The answer to an email query from one participant may be posted on the blog (without of course identifying the participant), for all to learn from: not just learners, but frequently the programme staff too. If a participant asks TQFE-Tutor for advice on recommended reading about a particular topic, the duty tutor's suggestions are shared with all via a blog posting, which may also subsequently be supplemented/improved by (blog) comments from learners and programme staff. Thereafter, enquiries on that topic may be referred to the relevant blog page. In the focus group, S2 commented on the valuable time saved by not having to "reinvent[ing] the wheel all the time" - referring again to the useful transparency of the system. S4 remarked that the central organisation of all relevant information - "one place for everything" - on TQFE-Tutor meant that no time was wasted searching through drives or folders.

\section{Resilience}

Focus group members spoke very positively about TQFE-Tutor's resilience. S3 remarked, "... if one of the team should go off sick... someone can just step into that role". Previously staff absence had often caused major disruption for the team; tutoring correspondence having been undertaken "privately" in its entirety between personal tutor and learner, remaining closed to colleagues during a staff absence. S4's comments concurred on this theme, commenting that in her work on other programmes any absences result in a build-up; communication with her students stops until she returns to tackle it, "pick up threads". In contrast, she recognised that with TQFE-Tutor the participants would not even know if anyone was absent. Seamless cover through shift swapping takes pressure off individuals and when absentees return it is easy to catch up as there is an "e-trail" in the folders. This means less stress for team members and consequently better support for learners.

Another aspect of the system's resilience - and with particular resonance in the context of staff development - emerges from the team all having to learn new skills as an everyday part of their jobs as part of the TQFE-Tutor staff roster. S1 commented on how she herself had been required "to learn how to post things on the blog" whereas tasks like this formerly fell only to those staff who were recognised within the team as having advanced IT skills.

\section{Weakness}

\section{Adherence to FAQs}

Protocols provided in the FAQs must be adhered to by all. "Private" correspondence between markers and participants, conducted via the marker's own email account (and hence not visible to the rest of the team), must be avoided; in the words of the 


\section{A. McGuigan and L. Golden}

facilitator of the focus group, “... it relies on everybody sticking to the protocols very heavily". While TQFE-Tutor has helped minimise the impact of a "maverick marker" on individual participants, the tutor on duty needs to follow protocol closely, to file, forward or reply to messages correctly and refer to the FAQs when unsure. An incoming piece of marking filed without copying the marker in, a report filed incorrectly or a folder mislaid can all cause problems. A duty tutor not reading the "backstory" in a participant's folder in the email account could result in the giving of inappropriate guidance or conflicting advice such as granting a further extension when a final deadline has been fixed, or adopting the wrong tone for example in the case of a family bereavement or mental health issues.

\section{Necessity of team ethos}

Members of the focus group discussed the issue that whilst in some respects at least, CPD ought to be attractive to all professionals, not everyone is motivated to the same extent to learn new skills. Some staff may become complacent, feeling their subject expertise is sufficient and the constantly changing new IT skills required for the online tutoring role too demanding. The success of TQFE-Tutor entirely depends on a strong team ethos and where this is absent the system breaks down.

\section{Over-dependence on email}

A continuing over-dependency on email correspondence has been noted and developments are in place to encourage further blog use to enable questions and solutions to be seen by all participants. Aware that some participants do need targeted support and an early identification of study support needs, a diagnostic strategy for extra support is being developed to attune the nature of the task to the perspective of the student (Jonassen 1994).

\section{Increase in administration}

As TQFE-Tutor becomes more widely known in the college sector here in Scotland, general enquiries of the kind formerly sent to administration - for instance regarding application procedures - are also now arriving in the TQFE-Tutor inbox. Staff are aware of a potential risk of academic staff taking on additional administrative tasks, more suited to a clerical support role.

\section{Conclusion}

A range of strengths and weaknesses emerged from the study. The staff team recognise that TQFE-Tutor has provided a lot of fresh opportunities for informal professional development. By opening access to one another's tutoring, team members experience the online equivalent of peer observation of teaching, and additionally receive a useful overview of the whole student cohort. TQFE-Tutor has engendered a welcome sense of belongingness in a team which rarely meets face-to-face. The time savings it offers are highly valued by the team, as is the resilience of the model. On the other hand, the team recognises some weaknesses too: a continuing over-dependence on email by some participants; the potential problem of individual members of the team not sharing the team ethos and adhering to the FAQs and a potential increase in 
administrative correspondence. Having identified these aspects of the system, the team is working towards reinforcing the strengths and minimising the weaknesses.

TQFE-Tutor underlines the importance of the "continuous" part of CPD. Engaging with current and future online learners necessitates staff keeping informed and conversant with an ever-changing field. This constant change presents challenges to online programme teams, but also the exhilaration and intellectual stimulation of being part of a contemporary transformation of education provision. The TQFETutor system introduces new ideas and supports not only programme participants but also tutor team members in making sense of these for themselves (see Driver et al. 1994). The online tutor's place of work is online and TQFE-Tutor ensures that professional development opportunities are located there too - as advocated by commentators such as Boud (1999) and more recently Cornelius and Macdonald (2008). Morrison (2012) writes of the need for “. . . a new academic, one that doesn't use the teaching f2f classroom as the yardstick, but incorporates and adapts pedagogy to the changing tools". By enabling colleagues to help each other "to become sophisticated and even expert" (University of New South Wales n.d.) in online pedagogy, TQFE-Tutor has been instrumental in developing a team of "new academics". For this and other reasons, the authors warmly commend the centralisation of communication and tutoring to other online programmes.

\section{References}

Bennett, S. \& Marsh, D. (2002) 'Are we expecting online tutors to run before they can walk?', Innovations in Education and Teaching International, vol. 39, no. 1, pp. 14-20.

Boud, D. (1999) 'Situating academic development in professional work: using peer learning', International Journal for Academic Development, vol. 4, no. 1, pp. 3-10.

Collison, G., et al. (2000) Facilitating Online Learning: Effective Strategies for Moderators, Atwood Publishing, Madison.

Cornelius, S. \& Macdonald, J. (2008) 'Online informal professional development for distance tutors: experiences from The Open University in Scotland', Open Learning: The Journal of Open, Distance and e-Learning, vol. 23, no. 1, pp. 43-55.

Driver, R., et al. (1994) 'Constructing scientific knowledge in the classroom', Educational Researcher, vol. 23, no. 7, pp. 5-12.

Fidishun, D. (n.d.) Andragogy and Technology: Integrating Adult Learning Theory as We Teach with Technology, Available at: http://frank.mtsu.edu/ itconf/proceed00/fidishun.htm.

Garrison, R. \& Anderson, T. (2003) E-learning in the 21st Century a Framework for Research and Practice, RoutledgeFalmer, Oxon.

Garrison, D. R., Anderson, T. \& Archer, W. (1999) 'Critical inquiry in a text-based environment: computer conferencing in higher education', The Internet and Higher Education, vol. 2, no. 2-3, pp. 87-105.

Garrison, R. \& Cleveland-Innes, M. (2005) 'Facilitating cognitive presence in online learning: interaction is not enough', The American Journal of Distance Education, vol. 19, no. 3, pp. $122-148$.

Jonassen, D. H. (1994) 'Thinking technology: towards a constructivist design model', Educational Technology, vol. 34, no. 4, pp. 34-37.

McLoughlin, C. \& Lee, M. (2010) 'Personalised and self-regulated learning in the Web 2.0 era: international exemplars of innovative pedagogy using social software', Australasian Journal of Educational Technology, vol. 26, no. 1, pp. 28-43.

Morrison, D. (2012) 'New online teaching model: sage-on-the-side', Online learning insights [blog], Available at: http://onlinelearninginsights.wordpress.com/2012/02/20/new-onlineteaching-model-sage-on-the-side/

Rice, C. (2011) Campus Technology 2012: What's Hot, What's Not, Available at: http:// campustechnology.com/Articles/2011/12/29/2012-Whats-Hot-Whats-Not.aspx?sc_lang= en\&Page $=4$. 


\section{A. McGuigan and L. Golden}

Richardson, J. T. E., Long, G. L. \& Woodley, A. (2003) 'Academic engagement and perceptions of quality in distance education', Open Learning, vol. 18, no. 3, pp. 223-244.

Ritchie, J. \& Spencer, L. (1994) 'Qualitative data analysis for applied policy research' in Analyzing Qualitative Data, eds A. Bryman \& R. G. Burgess, Taylor \& Francis, London, pp. 173-194.

Srivastava, A. \& Thomson, S. B. (2009) 'Framework analysis: a qualitative methodology for applied policy research', JOAAG, vol. 4, no. 2, Available at: http://joaag.com/uploads/ 06_Research_Note_Srivastava_and_Thomson_4_2_.pdf

Staker, H. (2011) The Rise of K12 Blended Learning, Available at: http://www.innosightinstitute. org/innosight/wp-content/uploads/2011/05/The-Rise-of-K-12-Blended-Learning.pdf

University of New South Wales (n.d.) Why is online teaching important? Available at: http:// youtu.be/EDULQMR6wJs

Yorke, M. (2004) 'Retention persistence and success in on campus higher education and their enhancement in open and distance learning', Open Learning, vol. 19, no. 1, pp. 19-32.

Zembylas, M. (2008) 'Adult learners' emotions in online learning', Distance Education, vol. 29, no. 1 , pp. $71-87$. 